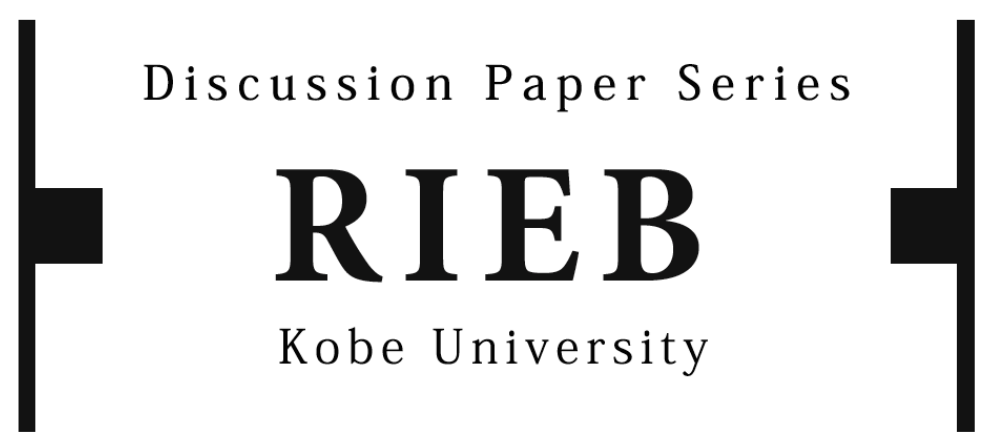

DP2014-06

\title{
Capital Accumulation through Studying Abroad and Return Migration*
}

\author{
Takumi NAITO \\ Laixun ZHAO
}

Revised March 5, 2014

* The Discussion Papers are a series of research papers in their draft form, circulated to encourage discussion and comment. Citation and use of such a paper should take account of its provisional character. In some cases, a written consent of the author may be required.

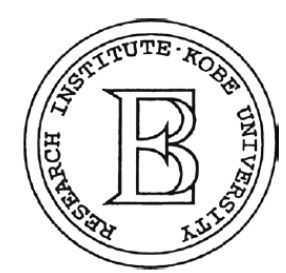

Research Institute for Economics and Business Administration Kobe University 


\title{
Capital Accumulation through Studying Abroad and Return Migration
}

\author{
Takumi Naito* \\ Laixun $\mathrm{Zhao}^{\dagger}$ \\ Waseda University \\ Kobe University
}

March 5, 2014

\begin{abstract}
This paper characterizes the interactions among studying abroad, return migration, and capital accumulation, in a two-country overlapping generations model with households of heterogeneous ability. The model exhibits positive selection of migration status (i.e., permanent, return, and non-migrants) based on ability, and over time, return migration increases as capital accumulates. Further, a decrease in the fixed cost of studying abroad and a simultaneous offsetting increase in the fixed cost of working abroad raise the relative supply of capital in the source country without decreasing anyone's utility. Nevertheless, any single change in either fixed cost cannot achieve it.
\end{abstract}

JEL classification: F22; I25; O15

Keywords: Capital accumulation; Studying abroad; Return migration; Heterogeneous ability; Positive selection; Brain gain

${ }^{*}$ Corresponding author. Takumi Naito. Faculty of Political Science and Economics, Waseda University, 1-6-1 Nishiwaseda, Shinjuku-ku, Tokyo 169-8050, Japan. E-mail: tnaito@waseda.jp.

${ }^{\dagger}$ Laixun Zhao. Research Institute for Economics and Business Administration, Kobe University, 2-1 Rokkodai-cho, Nada-ku, Kobe 657-8501, Japan. E-mail: zhao@rieb.kobeu.ac.jp. 


\section{Introduction}

Globalization renders studying abroad even more popular and necessary, not only for professional skills but also for different cultures and customs. World Bank data shows, the world annual growth rate of students studying abroad more than doubles that of world GDP growth from 1997 to $2011 .^{1}$ While many students from poor countries choose to stay in the host countries after completing their higher education, a phenomenon called "brain drain" that in the past has been a serious concern for the source countries as well as economists, ${ }^{2}$ recently a new trend has emerged, which is sometimes called "reverse brain drain" or "return migration". Specifically, initially some students return home with their human capital acquired abroad perhaps for family ties or due to government incentives. And as capital accumulates there, more and more highly-educated migrants are attracted to come back, to enjoy the improved working conditions. This trend is apparent for emerging economies such as China (e.g., Zweig, 2006) and India (e.g., Chacko, 2007). Also, MATT (2013) shows that between 2005 and 2010, 1.39 million people moved from the U.S. to Mexico, of whom 0.985 million were returning migrants. According to China Statistical Yearbook 2013, China's student return rate (i.e., the number of returned students divided by the number of students studying abroad) rose rapidly from $14.3 \%$ in 2002 to $68.3 \%$ in 2012; in 2012 alone, over 272,900 overseas students came back.

A natural question is then, who will return? Are the returnees those with the highest ability? Casual evidence shows that in academics, those with the highest ability are less likely to return because their research and work opportunities are better in the host countries. ${ }^{3}$ While in the business world, the situation is more mixed: some high-ability students remain permanent

\footnotetext{
${ }^{1}$ See World Bank Education Statistics, showing the number of students in tertiary education studying abroad increased from 1.67 million in 1997 to 3.77 million in 2011, with an annual average growth rate of $5.84 \%$; while $2.71 \%$ is the annual average growth rate of world GDP in constant 2005 U.S. dollars during the same period, calculated from World Development Indicators.

${ }^{2}$ The whole volume 95, issue 1 of Journal of Development Economics in 2011 is devoted to a Symposium on Globalization and Brain Drain.

${ }^{3}$ Numerous economics Nobel laureates are non-returnees, such as Leonid Hurwicz, Christopher Pissarides, Amartya Sen, etc.
} 
migrants, such as Satya Nadella and Fareed Zakaria, others choose to return, such as the founders of IT giants Baidu and Sohu in China. However, studies show that more prevalent is the case in which most returnees find jobs in government or foreign subsidiaries, indicating that they are perhaps of middle ability. ${ }^{4}$

The present paper attempts to model the above phenomena. We hope to characterize the interactions among studying abroad, return migration, and capital accumulation in the source country. To this end, we formulate a two-country, one-good, two-factor, two-period-lived overlapping generations model with households of heterogeneous ability. Ability is uniformly distributed over the unit interval. When young, a household in the source country first decides in which country to study. If she chooses to study abroad, she pays higher school fees in return for better human capital reflecting higher educational quality in the host country or higher required study effort. Further, after completing her study abroad, the foreign student decides whether to stay abroad or return home for work. If she chooses the latter, she gives up higher living standards in the host country but could save expensive costs of being a permanent resident. After settling in for work, each household chooses her savings for consumption when old.

The model straightforwardly derives a benchmark positive selection of migration status based on ability: households whose ability is above the higher cutoff both study and work abroad; those with ability below the lower cutoff stay at home; and those whose ability is in-between study abroad but return home for work. These match the facts mentioned above and the empirical evidence from Bulgaria and China that perhaps most returnees are of middle ability.

A novel finding of the present paper is the intergenerational linkages of migration. Specifically, the migration pattern of one generation depends on the relative capital stock of the two countries, which in turn depends on

\footnotetext{
${ }^{4}$ Ivanova (2013) shows that $81 \%$ of Bulgarian migrants go abroad to obtain education. For the non-returnees, better payment and better professional realization are the dominant reasons. Among those who return, most find work in government or foreign subsidiaries in Bulgaria, a job preference also confirmed by data from the Ministry of Education in China for most Chinese returnees.
} 
the migration pattern of the previous generation. Such intergenerational linkages create a positive relationship between return migration and capital accumulation over time: as more students with higher ability return home, the source country accumulates more savings (capital) for the next period. It in turn makes returning home more attractive for the next generation by raising its labor productivity. This explains for the empirical fact that only in the last decade has return migration become important for some emerging economies such as China and India, when capital accumulation has reached above a certain level.

Next on comparative dynamics, we find that a permanent decrease in the fixed cost of either studying or working abroad increases the fraction of permanent migrants but decreases the relative supply of capital in the source country. A decrease in the fixed cost of studying abroad increases the potential utility of permanent migrants more than return migrants because the former, also incurring the fixed cost of working abroad, has a higher marginal utility than the latter. This lowers the incentives for return migration. Then fewer people work and save in the source country, and the next period's relative capital stock falls from its old steady state value. This further induces more of the next generation to stay abroad, causing a "brain drain". Thus, simply encouraging young people to study or work abroad is harmful to capital accumulation in the source country.

However, a permanent decrease in the fixed cost of studying abroad and a simultaneous offsetting permanent increase in the fixed cost of working abroad is Pareto-improving. This increases the potential utility of the return migrants but leaves that of permanent migrants as well as non-migrants unchanged, inducing more people to study abroad and more of these students to return home, increasing the relative supply of capital in the source country for the next period, which further induces more of the next generation to study abroad and return home. Under such simultaneous changes in migration costs, "brain drain" is turned into "brain gain".

Several theoretical papers also study return migration in the literature. Borjas and Bratsberg (1996) and Dustmann et al. (2011) develop simple continuous-time models, and generate positive selection of migration sta- 
tus. ${ }^{5}$ However, they only consider return decisions of a single generation, ignoring intergenerational linkages. Dominguez Dos Santos and Postel-Vinay (2003) use an overlapping generations model similar to ours, but knowledge accumulation is specified only as an unintentional by-product of final good production. Also, the broader theoretical literature on return migration includes those on exogenous return (e.g., Galor and Stark, 1990; Lange, 2013), family decisions (e.g., Dustmann, 2003; Djajić, 2008), duration of stay (e.g., Dustmann 1997), and agglomeration and urban congestion (e.g., Fujishima, 2013). Remittance is the usual source of "brain gain".

By contrast, in our model studying abroad is a costly investment for future benefits each household faces. Return migration occurs not based on the traditional channel of brain gain-remittance, but due to capital accumulation through gains in acquired effective labor from studying abroad, which is novel. And as capital accumulates, more return migration arises, further increasing capital accumulation and inducing more return migration.

The rest of this paper is organized as follows. Section 2 sets up the model in autarky. Section 3 characterizes the equilibrium under free migration. Section 4 conducts comparative dynamics of migration costs. Section 5 concludes.

\section{Autarky}

Consider a closed economy $i(=S, N)$ with one final good (the numeraire), two factors (i.e., capital and effective labor), and two overlapping generations (i.e., young and old). In each period $t(=0,1,2, \ldots, \infty)$, the final good is produced from capital and effective labor under constant returns to scale and perfect competition. A household of generation $t$ is young in period $t$, and is old in period $t+1$. Each household is endowed with one unit of time for work or study when young, and ability $a_{t}^{i}$, which is uniformly distributed over the unit interval $[0,1]$. When young, each household chooses her educational level, supplies the resulting effective labor to earn the wage,

\footnotetext{
${ }^{5}$ Dustmann et al. (2011) derive a monotonic relationship between the ratio of two distinct skills and migration status.
} 
and chooses how much to consume at present or save for the future. In autarky, she cannot choose where to study, or where to work. When old, she earns the rental from her supply of capital, which is entirely spent for consumption. As is often the case with many two-period-lived overlapping generations models, we assume that capital depreciates fully in each period.

\section{$2.1 \quad$ Households}

A household of generation $t$ in country $i$ with ability $a_{t}^{i}$ maximizes her utility $U_{t}^{i}=\ln c_{t}^{i}+[1 /(1+\rho)] \ln d_{t+1}^{i}$, subject to:

$$
\begin{aligned}
c_{t}^{i}+s_{t}^{i} & =W_{t}^{i}, \\
d_{t+1}^{i} & =r_{t+1}^{i} s_{t}^{i}, \\
W_{t}^{i} & =w_{t}^{i}\left(1-e_{t}^{i}+h^{i}\left(e_{t}^{i} ; a_{t}^{i}\right)\right),
\end{aligned}
$$

with $r_{t+1}^{i}$ and $w_{t}^{i}$ given, where $c_{t}^{i}$ is consumption when young; $\rho(>0)$ is the subjective discount rate, which is assumed to be the same for all households and countries; $d_{t+1}^{i}$ is consumption when old; $s_{t}^{i}$ is savings; $W_{t}^{i}$ is the total income; $r_{t+1}^{i}$ is the rental rate; $w_{t}^{i}$ is the wage rate; $e_{t}^{i}$ is the time for study; and $h^{i}$ is the acquired effective labor. Eqs. (1) and (2) represent the budget constraints when young and old, respectively. Eq. (3) means that the total income is the wage rate multiplied by the effective labor, which consists of the time for work and the acquired effective labor. By investing $e_{t}^{i}$ units of time in education, a household can get $h^{i}\left(e_{t}^{i} ; a_{t}^{i}\right)$ units of the acquired effective labor. The functional form of $h^{i}(\cdot)$ will be specified later.

A household's utility maximization problem is solved backward. First, substituting Eqs. (1) and (2) into the utility function, we choose $s_{t}^{i}$ to maximize $U_{t}^{i}=\ln \left(W_{t}^{i}-s_{t}^{i}\right)+[1 /(1+\rho)]\left(\ln r_{t+1}^{i}+\ln s_{t}^{i}\right)$, with $W_{t}^{i}$ and $r_{t+1}^{i}$ given. This results in the following savings function:

$$
s_{t}^{i}=W_{t}^{i} /(2+\rho)
$$

Substituting Eq. (4) back into the utility function, the latter is rewritten 


$$
\begin{aligned}
U_{t}^{i} & =C+[1 /(1+\rho)] V_{t}^{i} ; \\
C & \equiv \ln [(1+\rho) /(2+\rho)]+[1 /(1+\rho)] \ln [1 /(2+\rho)], \\
V_{t}^{i} & \equiv(2+\rho) \ln W_{t}^{i}+\ln r_{t+1}^{i} .
\end{aligned}
$$

Since $\rho$ and hence $C$ are exogenous and constant, individual utility across different states can be compared only in terms of $V_{t}^{i}$. Second, in view of Eq. (3), maximizing $V_{t}^{i}$ with $r_{t+1}^{i}$ and $w_{t}^{i}$ given requires maximizing the amount of effective labor $1-e_{t}^{i}+h^{i}\left(e_{t}^{i} ; a_{t}^{i}\right)$ with respect to $e_{t}^{i}$. Before determining $e_{t}^{i}$, we impose some conditions on the acquired effective labor functions:

\section{Assumption 1}

$$
\begin{aligned}
h^{i}\left(0 ; a_{t}^{i}\right) & =0, \\
h_{e}^{i}\left(e_{t}^{i} ; a_{t}^{i}\right) & >0, h_{e e}^{i}\left(e_{t}^{i} ; a_{t}^{i}\right)<0, \\
h_{a}^{i}\left(e_{t}^{i} ; a_{t}^{i}\right) & >0, h_{e a}^{i}\left(e_{t}^{i} ; a_{t}^{i}\right)>0, \\
h_{e}^{i}\left(0 ; a_{t}^{i}\right) & >1>h_{e}^{i}\left(1 ; a_{t}^{i}\right), \\
h_{e}^{S}\left(e_{t} ; a_{t}\right) & <h_{e}^{N}\left(e_{t} ; a_{t}\right), \\
h_{a}^{S}\left(e_{t} ; a_{t}\right) & <h_{a}^{N}\left(e_{t} ; a_{t}\right) .
\end{aligned}
$$

Households cannot have acquired effective labor without studying. The returns to study time are positive but diminishing. The more able a person is, the more acquired effective labor and returns to study time she has. We ensure an interior solution for study time. The returns to both study time and ability are higher in the developed country $N$ than in the developing country $S$. The last statement reflects better educational quality in country $N$.

Under Assumption 1, a household's optimal study time is given by:

$$
-1+h_{e}^{i}\left(e_{t}^{i} ; a_{t}^{i}\right)=0 \Rightarrow e_{t}^{i}=e^{i}\left(a_{t}^{i}\right) \in(0,1) \forall t .
$$


Substituting Eq. (6) back into $1-e_{t}^{i}+h^{i}\left(e_{t}^{i} ; a_{t}^{i}\right)$, the maximized effective labor is obtained as:

$$
1-e^{i}\left(a_{t}^{i}\right)+h^{i}\left(e^{i}\left(a_{t}^{i}\right) ; a_{t}^{i}\right)=1+\int_{0}^{e^{i}\left(a_{t}^{i}\right)}\left(h_{e}^{i}\left(e_{t}^{i} ; a_{t}^{i}\right)-h_{e}^{i}\left(e^{i}\left(a_{t}^{i}\right) ; a_{t}^{i}\right)\right) d e_{t}^{i} \equiv E^{i}\left(a_{t}^{i}\right)>1 \forall t .
$$

From Eqs. (6), (7), and Assumption 1, it is easily verified that:

$$
\begin{aligned}
e^{S}\left(a_{t}\right) & <e^{N}\left(a_{t}\right) \forall a_{t}, \\
E^{S}\left(a_{t}\right) & <E^{N}\left(a_{t}\right) \forall a_{t} .
\end{aligned}
$$

A person in country $N$ studies more, and thus has more effective labor, than a person with the same ability in country $S$.

We next examine how study time and maximized effective labor depend on ability. Totally differentiating Eq. (6), we have:

$$
e_{a}^{i}\left(a_{t}^{i}\right) \equiv d e^{i}\left(a_{t}^{i}\right) / d a_{t}^{i}=-h_{e a}^{i}\left(e^{i}\left(a_{t}^{i}\right) ; a_{t}^{i}\right) / h_{e e}^{i}\left(e^{i}\left(a_{t}^{i}\right) ; a_{t}^{i}\right)>0 .
$$

Differentiating Eq. (7), and using Eq. (6), we obtain:

$$
E_{a}^{i}\left(a_{t}^{i}\right) \equiv d E^{i}\left(a_{t}^{i}\right) / d a_{t}^{i}=\left(-1+h_{e}^{i}\left(e^{i}\left(a_{t}^{i}\right) ; a_{t}^{i}\right)\right) e_{a}^{i}\left(a_{t}^{i}\right)+h_{a}^{i}\left(e^{i}\left(a_{t}^{i}\right) ; a_{t}^{i}\right)=h_{a}^{i}\left(e^{i}\left(a_{t}^{i}\right) ; a_{t}^{i}\right)>0 .
$$

Eqs. (10) and (11) say that a person studies more and has more effective labor, the more able she is. Finally, from Eqs. (8), (11), and Assumption 1, we have:

$$
E_{a}^{S}\left(a_{t}\right)=h_{a}^{S}\left(e^{S}\left(a_{t}\right) ; a_{t}\right)<h_{a}^{N}\left(e^{S}\left(a_{t}\right) ; a_{t}\right)<h_{a}^{N}\left(e^{N}\left(a_{t}\right) ; a_{t}\right)=E_{a}^{N}\left(a_{t}\right) \forall a_{t} .
$$

Eqs. (8), (9), and (12) suggest the potential benefits of studying abroad for people born in country $S$. By moving to country $N$, one studies harder and hence gets more effective labor. Moreover, the gain in the effective labor 
from studying abroad is larger, the more able a person is.

\section{$2.2 \quad$ Firms}

The representative firm maximizes its profit $\Pi_{t}^{i}=Y_{t}^{i}-r_{t}^{i} K_{t}^{i}-w_{t}^{i} L_{t}^{i}$, subject to the production function $Y_{t}^{i}=B^{i}\left(K_{t}^{i}\right)^{\alpha}\left(L_{t}^{i}\right)^{1-\alpha}$, with $r_{t}^{i}$ and $w_{t}^{i}$ given, where $Y_{t}^{i}$ is the supply of the final good; $K_{t}^{i}$ is the demand for capital; $L_{t}^{i}$ is the demand for effective labor; $B^{i}(>0)$ is the productivity; and $\alpha(\in(0,1))$ is the Cobb-Douglas cost share of capital, which is assumed to be the same in both countries. As usual, the first-order conditions for profit maximization are:

$$
\begin{aligned}
r_{t}^{i} & =\alpha B^{i}\left(k_{t}^{i}\right)^{\alpha-1}, \\
w_{t}^{i} & =(1-\alpha) B^{i}\left(k_{t}^{i}\right)^{\alpha},
\end{aligned}
$$

where $k_{t}^{i} \equiv K_{t}^{i} / L_{t}^{i}$ is the capital/effective labor ratio.

\section{$2.3 \quad$ Markets}

Noting that ability is uniformly distributed over the unit interval, the marketclearing conditions for capital, effective labor, and the final good are given by, respectively:

$$
\begin{aligned}
K_{t}^{i} & =\int_{0}^{1} s_{t-1}^{i}\left(a_{t-1}^{i}\right) d a_{t-1}^{i}, \\
L_{t}^{i} & =\int_{0}^{1} E^{i}\left(a_{t}^{i}\right) d a_{t}^{i}, \\
Y_{t}^{i} & =\int_{0}^{1}\left(c_{t}^{i}\left(a_{t}^{i}\right)+s_{t}^{i}\left(a_{t}^{i}\right)\right) d a_{t}^{i}+\int_{0}^{1} d_{t}^{i}\left(a_{t-1}^{i}\right) d a_{t-1}^{i} .
\end{aligned}
$$

On the other hand, from Eqs. (1), (2), (3), (7), (13), and (14), we obtain Walras' law, requiring that the sum of the values of the excess demands for all markets is identically zero. Therefore, we need to use all but the last market-clearing conditions to characterize the equilibrium. 


\subsection{Dynamic system}

Rewriting Eq. (15) with one period forward using Eq. (3), (4), (7), and (14), we have $K_{t+1}^{i}=\left[(1-\alpha) B^{i}\left(k_{t}^{i}\right)^{\alpha} /(2+\rho)\right] \int_{0}^{1} E^{i}\left(a_{t}^{i}\right) d a_{t}^{i}$. The integral part is equal to $L_{t}^{i}$ from Eq. (16), but it is also equal to $L_{t+1}^{i}$ because the ability distribution is constant over time in the present case without migration. Dividing this equation by $L_{t+1}^{i}$, we obtain:

$$
k_{t+1}^{i}=\left[(1-\alpha) B^{i} /(2+\rho)\right]\left(k_{t}^{i}\right)^{\alpha} .
$$

Eq. (18) is an autonomous one-dimensional first-order difference equation with respect to $k_{t}^{i}$. Since $K_{t}^{i}$ is a state variable, and the constant ability distribution implies the constant supply of effective labor, $k_{t}^{i}$ is also a state variable. As is clear from Eq. (18), the dynamics of $k_{t}^{i}$ is the same as the standard Diamond OLG model. Let us define a steady state as a situation where all variables grow at constant rates. In the present case, $k_{t}^{i}$ is constant in a steady state: $k_{t}^{i}=k_{t+1}^{i}=\bar{k}^{i}$, where a bar over a variable represents a steady state under autarky. From Eq. (18), $\bar{k}^{i}$ is uniquely determined as:

$$
\bar{k}^{i}=\left[(1-\alpha) B^{i} /(2+\rho)\right]^{1 /(1-\alpha)} .
$$

Since $k_{t+1}^{i}>k_{t}^{i}$ if and only if $k_{t}^{i}<\bar{k}^{i}$, for any initial condition $k_{0}^{i}(>0)$, $k_{t}^{i}$ approaches monotonically to $\bar{k}^{i}$.

\subsection{Individual utility in the steady state}

Now we can compare utility of two agents in the two countries having the same ability. Using Eqs. (3), (7), (13), (14), and (18), the variable part $V_{t}^{i}$ of the indirect utility function (5) is rewritten as:

$$
\begin{gathered}
V_{t}^{i}\left(a_{t}^{i}\right)=D+(2+\rho+\alpha) \ln B^{i}+(1+\rho+\alpha) \alpha \ln k_{t}^{i}+(2+\rho) \ln E^{i}\left(a_{t}^{i}\right) \\
D \equiv(1+\rho+\alpha) \ln (1-\alpha)+\ln \alpha+(\alpha-1) \ln [1 /(2+\rho)] .
\end{gathered}
$$


Here we make a reasonable assumption that firms in country $N$ are more productive than in country $S$ :

\section{Assumption 2}

$$
B^{S}<B^{N}
$$

Then, from Eq. (19), we can immediately say that country $N$ has a higher capital/effective labor ratio than country $S$ in the steady state:

$$
\bar{k}^{S}<\bar{k}^{N} \text {. }
$$

Consequently, from Eqs. (9) and (20), we obtain:

$$
\bar{V}^{S}\left(a_{t}\right)<\bar{V}^{N}\left(a_{t}\right) \forall a_{t} .
$$

For any common ability, a person in country $N$ attains higher utility than in country $S$ in the steady state. This comes from both macroeconomic and microeconomic conditions. The higher productivity and the resulted higher capital/effective labor ratio in country $N$ contribute to higher utility in country $N$. Not only that, a person in country $N$ studies harder and hence supplies more effective labor. One important implication from this result is that, if there were no migration cost, all households in country $S$ would like to emigrate to country $N$. The actual migration pattern will be characterized by the tradeoff between such utility gains and migration costs.

\section{Free migration}

Suppose that the two closed economies $S$ and $N$ allow migration as well as trade in the final good with each other. Since only households in country $S$ have an incentive to go abroad, we describe their behavior in detail. When young, each household first chooses in which country to study. Studying in country $N$ requires a fixed cost of $f$ such as application and tuition fees (in excess of those at home) in units of effective labor. After studying abroad, each foreign student has two options and must make a decision 
again: returning to her source country $S$, or staying at her host country $N$. In the latter case, she has to pay an extra fixed cost of working abroad $g$ in terms of effective labor, including costs of applying for a permanent residence permit, costs of adjusting to a foreign work environment, and so on. Both $f$ and $g$ are assumed to be the same for all households. Each household supplies her effective labor, and spends the resulting wage for consumption or savings in the country she works. When old, she spends the whole rental income for consumption.

Based on this setup, there are three types of households born in country $S: j=S, R, M$. Type $S$ stays in her home country for study and work; type $R$ studies abroad, and then returns to her home country for work; and type $M$ studies and works abroad as a permanent migrant. ${ }^{6}$ The total incomes net of the migration costs for types $S, R$, and $M$ are given by, respectively:

$$
\begin{aligned}
W_{t}^{S} & =w_{t}^{S}\left(1-e_{t}^{S}+h^{S}\left(e_{t}^{S} ; a_{t}^{S}\right)\right), \\
W_{t}^{R} & =w_{t}^{S}\left(1-e_{t}^{R}+h^{N}\left(e_{t}^{R} ; a_{t}^{S}\right)-f\right), \\
W_{t}^{M} & =w_{t}^{N}\left(1-e_{t}^{M}+h^{N}\left(e_{t}^{M} ; a_{t}^{S}\right)-f-g\right) .
\end{aligned}
$$

Compared with type $S$, types $R$ and $M$ give up $f$ units of effective labor in exchange for higher quality of education. Moreover, type $M$ forgoes another $g$ units of effective labor to obtain a higher wage rate in country $N$.

\subsection{Households}

Just like the autarky case, we can show that maximizing individual utility requires maximizing the amount of effective labor for each migration type. Considering the acquired effective labor functions applied to each type, we immediately know that both types $R$ and $M$ behave in the same way as country $N$ 's households, whereas type $S$ does not change her behavior from autarky:

\footnotetext{
${ }^{6}$ In order to focus on decisions whether to study abroad and return home, we assume away another type who studies at home and then goes abroad for work. This is true when the costs of working abroad are prohibitively high for such a type.
} 


$$
\begin{aligned}
e_{t}^{S} & =e^{S}\left(a_{t}^{S}\right), \\
e_{t}^{R} & =e_{t}^{M}=e^{N}\left(a_{t}^{S}\right)>e^{S}\left(a_{t}^{S}\right), \\
1-e_{t}^{S}+h^{S}\left(e_{t}^{S} ; a_{t}^{S}\right) & =E^{S}\left(a_{t}^{S}\right), \\
1-e_{t}^{R}+h^{N}\left(e_{t}^{R} ; a_{t}^{S}\right) & =1-e_{t}^{M}+h^{N}\left(e_{t}^{M} ; a_{t}^{S}\right)=E^{N}\left(a_{t}^{S}\right)>E^{S}\left(a_{t}^{S}\right),
\end{aligned}
$$

where $e^{N}\left(a_{t}^{S}\right)$ and $E^{N}\left(a_{t}^{S}\right)$ have the same functional forms as $e^{N}\left(a_{t}^{N}\right)$ and $E^{N}\left(a_{t}^{N}\right)$ in Eqs. (6) and (7), respectively. Substituting Eqs. (21) and (22) back into the definitions of the total incomes $W_{t}^{j}$, the variable parts $V_{t}^{j}$ of the indirect utility functions (5) for the three types are given by:

$$
\begin{aligned}
V_{t}^{S}\left(a_{t}^{S}\right) & =(2+\rho) \ln w_{t}^{S}+\ln r_{t+1}^{S}+(2+\rho) \ln E^{S}\left(a_{t}^{S}\right), \\
V_{t}^{R}\left(a_{t}^{S}\right) & =(2+\rho) \ln w_{t}^{S}+\ln r_{t+1}^{S}+(2+\rho) \ln \left(E^{N}\left(a_{t}^{S}\right)-f\right), \\
V_{t}^{M}\left(a_{t}^{S}\right) & =(2+\rho) \ln w_{t}^{N}+\ln r_{t+1}^{N}+(2+\rho) \ln \left(E^{N}\left(a_{t}^{S}\right)-f-g\right) .
\end{aligned}
$$

Let us define two cutoff abilities $a_{t}^{R}$ and $a_{t}^{M}$ such that:

$$
\begin{aligned}
V_{t}^{S}\left(a_{t}^{R}\right) & =V_{t}^{R}\left(a_{t}^{R}\right), \\
V_{t}^{R}\left(a_{t}^{M}\right) & =V_{t}^{M}\left(a_{t}^{M}\right) .
\end{aligned}
$$

To make the model interesting, we impose the following conditions:

\section{Assumption $3^{7}$}

\footnotetext{
${ }^{7}$ Although the last two conditions include the factor prices as endogenous variables at this point, later on we will derive parameter restrictions for them to hold in the steady state.
} 


$$
\begin{aligned}
E^{N}(0)-E^{S}(0) & <f<E^{N}(1)-E^{S}(1), \\
V_{t}^{R}\left(a_{t}^{R}\right) & >V_{t}^{M}\left(a_{t}^{R}\right), \\
V_{t}^{R}(1) & <V_{t}^{M}(1) .
\end{aligned}
$$

The first condition is necessary for coexistence of types $S$ and $R$. If $f$ were too small, then no one would stay home for study; and if $f$ were too large, then no one would go abroad for study. The second and third conditions, together with Eqs. (24) and (25), are necessary for coexistence of types $R$ and $M$. If $g$ were too small, then no foreign student would return home for work; and if $g$ were too large, then no foreign student would stay abroad for work. Under Assumption 3, the following proposition characterizes the pattern of migration:

Proposition 1 In each period, there exists a unique pair $\left(a_{t}^{R}, a_{t}^{M}\right)$ such that $0<a_{t}^{R}<a_{t}^{M}<1$. Moreover, such $a_{t}^{R}$ is time-invariant and increasing in $f$ :

$$
f=E^{N}\left(a_{t}^{R}\right)-E^{S}\left(a_{t}^{R}\right) \Rightarrow a_{t}^{R}=a^{R}(f) \forall t .
$$

Households born in country $S$ whose abilities are in $\left[0, a^{R}\right],\left[a^{R}, a_{t}^{M}\right]$, and $\left[a_{t}^{M}, 1\right]$ become types $S, R$, and $M$, respectively.

Proof. From Eqs. (23) and (24), Eq. (26) is equivalent to $E^{S}\left(a_{t}^{R}\right)=$ $E^{N}\left(a_{t}^{R}\right)-f$, or Eq. (28). From Eqs. (9) and (12), $E^{N}\left(a_{t}^{S}\right)-E^{S}\left(a_{t}^{S}\right)$ is positive and increasing in $a_{t}^{S}$. Therefore, under the first condition of Assumption 3 , there exists a unique $a_{t}^{R} \in(0,1)$. Since Eq. (28) does not contain any time-varying variable, $a_{t}^{R}=a^{R}(f)$ is constant over time. From Eqs. (12) and (28), $a^{R}$ is increasing in $f$. For all $a_{t}^{S}<a^{R}$, we have $f>E^{N}\left(a_{t}^{S}\right)-E^{S}\left(a_{t}^{S}\right)$, or $V_{t}^{S}\left(a_{t}^{S}\right)>V_{t}^{R}\left(a_{t}^{S}\right)$. Similarly, $V_{t}^{S}\left(a_{t}^{S}\right)<V_{t}^{R}\left(a_{t}^{S}\right)$ for all $a_{t}^{S}>a^{R}$.

Next, to compare Eqs. (24) and (25), we first realize that $\partial V_{t}^{M}\left(a_{t}^{S}\right) / \partial a_{t}^{S}=$ $(2+\rho) E_{a}^{N}\left(a_{t}^{S}\right) /\left(E^{N}\left(a_{t}^{S}\right)-f-g\right)>(2+\rho) E_{a}^{N}\left(a_{t}^{S}\right) /\left(E^{N}\left(a_{t}^{S}\right)-f\right)=\partial V_{t}^{R}\left(a_{t}^{S}\right) / \partial a_{t}^{S} \forall a_{t}^{S}$. Hence, under the second and third conditions of Assumption 3, there exists a unique $a_{t}^{M} \in\left(a^{R}, 1\right)$. For all $a_{t}^{S}<a_{t}^{M}$, we have $V_{t}^{R}\left(a_{t}^{S}\right)>V_{t}^{M}\left(a_{t}^{S}\right)$. 
Similarly, $V_{t}^{R}\left(a_{t}^{S}\right)<V_{t}^{M}\left(a_{t}^{S}\right)$ for all $a_{t}^{S}>a_{t}^{M}$.

Combining these results, we have $V_{t}^{S}\left(a_{t}^{S}\right) \geq V_{t}^{R}\left(a_{t}^{S}\right)>V_{t}^{M}\left(a_{t}^{S}\right)$ for $a_{t}^{S} \in$ $\left[0, a^{R}\right] ; V_{t}^{R}\left(a_{t}^{S}\right) \geq V_{t}^{S}\left(a_{t}^{S}\right)$ and $V_{t}^{R}\left(a_{t}^{S}\right) \geq V_{t}^{M}\left(a_{t}^{S}\right)$ for $a_{t}^{S} \in\left[a^{R}, a_{t}^{M}\right]$; and $V_{t}^{M}\left(a_{t}^{S}\right) \geq V_{t}^{R}\left(a_{t}^{S}\right)>V_{t}^{S}\left(a_{t}^{S}\right)$ for $a_{t}^{S} \in\left[a_{t}^{M}, 1\right]$.

Fig. 1 illustrates the distribution of migration types under Assumption 3 in $\left(a_{t}^{S}, V_{t}^{j}\right)$ plane. Curves $V_{t}^{S}, V_{t}^{R}$, and $V_{t}^{M}$ stand for Eqs. (23), (24), and (25), respectively. The two cutoffs $a^{R}$ and $a_{t}^{M}$ are determined at points $\mathrm{A}$ and $\mathrm{B}$, respectively. They partition the unit interval into three subsets, $\left[0, a^{R}\right],\left[a^{R}, a_{t}^{M}\right]$, and $\left[a_{t}^{M}, 1\right]$. First, households with low abilities $a_{t}^{S} \in\left[0, a^{R}\right]$ stay home because their gains from studying or working abroad cannot cover the fixed costs. Second, households with intermediate abilities $a_{t}^{S} \in\left[a^{R}, a_{t}^{M}\right]$ study abroad but return home for work. Although their ability is sufficiently high to cover the fixed cost of studying abroad, their gains from working abroad are not as high as returning home. Third, households with $a_{t}^{S} \in$ $\left[a_{t}^{M}, 1\right]$ are able enough to study and work abroad. Thus, households with different abilities are sorted into different migration types: the more able a person is, the more likely she is to study and work abroad. The measures of sets $\left[0, a^{R}\right],\left[a^{R}, a_{t}^{M}\right]$, and $\left[a_{t}^{M}, 1\right]$ are $a^{R}, a_{t}^{M}-a^{R}$, and $1-a_{t}^{M}$, which represent the fractions of types $S, R$, and $M$, respectively.

Proposition 1 says that the cutoff between types $S$ and $R$ is timeinvariant because changes in factor prices affect them equally as they both work in their home country. However, since types $R$ and $M$ work in different countries, the cutoff between them depends on different macroeconomic conditions in the two countries, which in turn depend on the cutoff itself through factor markets.

\subsection{Markets}

The market-clearing conditions for capital and effective labor in the two countries are given by, respectively: 


$$
\begin{aligned}
K_{t}^{S} & =\int_{0}^{a^{R}} s_{t-1}^{S}\left(a_{t-1}^{S}\right) d a_{t-1}^{S}+\int_{a^{R}}^{a_{t-1}^{M}} s_{t-1}^{R}\left(a_{t-1}^{S}\right) d a_{t-1}^{S}, \\
L_{t}^{S} & =\int_{0}^{a^{R}} E^{S}\left(a_{t}^{S}\right) d a_{t}^{S}+\int_{a^{R}}^{a_{t}^{M}}\left(E^{N}\left(a_{t}^{S}\right)-f\right) d a_{t}^{S}, \\
K_{t}^{N} & =\int_{0}^{1} s_{t-1}^{N}\left(a_{t-1}^{N}\right) d a_{t-1}^{N}+\int_{a_{t-1}^{M}}^{1} s_{t-1}^{M}\left(a_{t-1}^{S}\right) d a_{t-1}^{S}, \\
L_{t}^{N} & =\int_{0}^{1} E^{N}\left(a_{t}^{N}\right) d a_{t}^{N}+\int_{a_{t}^{M}}^{1}\left(E^{N}\left(a_{t}^{S}\right)-f-g\right) d a_{t}^{S},
\end{aligned}
$$

where the constancy of $a^{R}$ from Eq. (28) is considered. The world market-clearing condition for the final good is omitted to save space. It is important to note how different types of migrants contribute to factor markets. Households of type $M$, the permanent migrants, supply effective labor and capital in the host country. On the other hand, households of type $R$, the return migrants, participate in factor markets in the source country. From Eqs. (1), (2), (3), (7), (13), (14), (21), and (22), we can derive Walras' law. This implies that Eqs. (29), (30), (31), and (32) are enough, whereas the world market-clearing condition for the final good is redundant, to characterize an equilibrium. ${ }^{8}$

\subsection{Dynamic system}

From Eqs. (3), (4), (7), (14), (21), (22), (28), (29), (30), (31), and (32), we obtain:

\footnotetext{
${ }^{8}$ In fact, as long as the factor market-clearing conditions are met, the demand for the final good is equal to its supply within each country. In other words, trade in the final good does not occur even if allowed. This is not surprising because there is only one final good.
} 


$$
\begin{aligned}
k_{t+1}^{S} & =\left[(1-\alpha) B^{S} /(2+\rho)\right]\left(k_{t}^{S}\right)^{\alpha} L^{S}\left(a^{R}, a_{t}^{M}\right) / L^{S}\left(a^{R}, a_{t+1}^{M}\right) ; \\
L^{S}\left(a^{R}, a_{t}^{M}\right) & \equiv \int_{0}^{a^{R}} E^{S}\left(a_{t}^{S}\right) d a_{t}^{S}+\int_{a^{R}}^{a_{t}^{M}}\left(E^{N}\left(a_{t}^{S}\right)-f\right) d a_{t}^{S}, \\
k_{t+1}^{N} & =\left[(1-\alpha) B^{N} /(2+\rho)\right]\left(k_{t}^{N}\right)^{\alpha} L^{N}\left(a_{t}^{M}\right) / L^{N}\left(a_{t+1}^{M}\right) ; \\
L^{N}\left(a_{t}^{M}\right) & \equiv \int_{0}^{1} E^{N}\left(a_{t}^{N}\right) d a_{t}^{N}+\int_{a_{t}^{M}}^{1}\left(E^{N}\left(a_{t}^{S}\right)-f-g\right) d a_{t}^{S} .
\end{aligned}
$$

Compared with Eq. (18), Eqs. (33) and (34) indicate that the evolution of the capital/effective labor ratios is affected by migration. For example, when $a_{t}^{M}$ increases to $a_{t+1}^{M}$, more households return to their home country (because $a_{t}^{M}-a^{R}$ increases), and so the capital/effective labor ratio in country $S$ decreases whereas that in country $N$ increases in period $t+1$.

Using Eqs. (13), (14), (20), (33), and (34), Eqs. (23), (24), and (25) are rewritten as:

$$
\begin{aligned}
V_{t}^{S}\left(a_{t}^{S}\right) & =D+(2+\rho+\alpha) \ln B^{S}+(1+\rho+\alpha) \alpha \ln k_{t}^{S}+(2+\rho) \ln E^{S}\left(a_{t}^{S}\right) \\
& +(1-\alpha) \ln \left(L^{S}\left(a^{R}, a_{t+1}^{M}\right) / L^{S}\left(a^{R}, a_{t}^{M}\right)\right), \\
V_{t}^{R}\left(a_{t}^{S}\right) & =D+(2+\rho+\alpha) \ln B^{S}+(1+\rho+\alpha) \alpha \ln k_{t}^{S}+(2+\rho) \ln \left(E^{N}\left(a_{t}^{S}\right)-f\right) \\
& +(1-\alpha) \ln \left(L^{S}\left(a^{R}, a_{t+1}^{M}\right) / L^{S}\left(a^{R}, a_{t}^{M}\right)\right), \\
V_{t}^{M}\left(a_{t}^{S}\right) & =D+(2+\rho+\alpha) \ln B^{N}+(1+\rho+\alpha) \alpha \ln k_{t}^{N}+(2+\rho) \ln \left(E^{N}\left(a_{t}^{S}\right)-f-g\right) \\
& +(1-\alpha) \ln \left(L^{N}\left(a_{t+1}^{M}\right) / L^{N}\left(a_{t}^{M}\right)\right) .
\end{aligned}
$$

The last terms in Eqs. (35), (36), and (37) reflect the aforementioned demographic effects of migration on individual utility. A decrease in $k_{t+1}^{S}$ caused by an increase in $a_{t}^{M}$ to $a_{t+1}^{M}$, for example, raises country $S$ 's rental rate in period $t+1$, which raises utility of types $S$ and $R$ of generation $t$. In other words, an increase in a country's working population is good for its close older generation.

In deriving our dynamic system, let us define $\kappa_{t} \equiv K_{t}^{S} / K_{t}^{N}$ as the relative 
supply of capital in country $S$ to country $N$. Rewriting Eqs. (33) and (34) to obtain the expressions for $K_{t+1}^{S}$ and $K_{t+1}^{N}$, and dividing the former by the latter, we have:

$\kappa_{t+1}=B \kappa_{t}^{\alpha} \lambda\left(a^{R}, a_{t}^{M}\right)^{1-\alpha} ; B \equiv B^{S} / B^{N}<1, \lambda\left(a^{R}, a_{t}^{M}\right) \equiv L^{S}\left(a^{R}, a_{t}^{M}\right) / L^{N}\left(a_{t}^{M}\right)$,

where $\lambda\left(a^{R}, a_{t}^{M}\right)$ is the relative supply of effective labor in country $S$ to country $N$. Its partial derivatives are calculated as:

$$
\begin{aligned}
\lambda_{R}\left(a^{R}, a_{t}^{M}\right) & \equiv \partial \lambda\left(a^{R}, a_{t}^{M}\right) / \partial a^{R}=\left[E^{S}\left(a^{R}\right)-\left(E^{N}\left(a^{R}\right)-f\right)\right] / L^{N}\left(a_{t}^{M}\right)=0, \\
\lambda_{M}\left(a^{R}, a_{t}^{M}\right) & \equiv \partial \lambda\left(a^{R}, a_{t}^{M}\right) / \partial a_{t}^{M} \\
& =\left[\left(E^{N}\left(a_{t}^{M}\right)-f\right) L^{N}\left(a_{t}^{M}\right)+L^{S}\left(a^{R}, a_{t}^{M}\right)\left(E^{N}\left(a_{t}^{M}\right)-f-g\right)\right] / L^{N}\left(a_{t}^{M}\right)^{2}>0 .
\end{aligned}
$$

An increase in $a_{t}^{M}$ increases $L^{S}$ but decreases $L^{N}$, both of which increase $\lambda$. On the other hand, an increase in $a^{R}$ has no effect on $\lambda$ because an increase in $L^{S}$ by $E^{S}\left(a^{R}\right)$ is exactly offset by a decrease in $L^{S}$ by $E^{N}\left(a^{R}\right)-f$.

Substituting Eqs. (36) and (37) into Eq. (27), we obtain:

$$
\begin{aligned}
0 & =(2+\rho+\alpha) \ln B+(1+\rho+\alpha) \alpha\left(\ln \kappa_{t}-\ln \lambda\left(a^{R}, a_{t}^{M}\right)\right) \\
& +(2+\rho)\left(\ln \left(E^{N}\left(a_{t}^{M}\right)-f\right)-\ln \left(E^{N}\left(a_{t}^{M}\right)-f-g\right)\right) \\
& +(1-\alpha)\left(\ln \lambda\left(a^{R}, a_{t+1}^{M}\right)-\ln \lambda\left(a^{R}, a_{t}^{M}\right)\right) .
\end{aligned}
$$

The right-hand side of Eq. (41) is interpreted as the net benefit of changing from a permanent migrant to a return migrant for a household of generation $t$ born in country $S$. The first and second terms represent costs of returning home: country $S$ is relatively less productive, and probably has a lower capital/effective labor ratio, than country $N .^{9}$ The third term shows

\footnotetext{
${ }^{9}$ Country $S$ 's capital/effective labor ratio relative to country $N$ is $k_{t}^{S} / k_{t}^{N}=$
} 
a benefit of returning home in that it saves the fixed cost of working abroad. The fourth term captures the demographic effects of migration mentioned above. It can be either positive or negative, depending on whether $a_{t+1}^{M}$ increases or decreases from $a_{t}^{M}$.

Eqs. (38) and (41), together with the initial condition $\kappa_{0}=K_{0}^{S} / K_{0}^{N}(>$ $0)$, constitute an autonomous system of two-dimensional first-order difference equations with respect to a state variable $\kappa_{t}$ and a control variable $a_{t}^{M}$. Once an equilibrium path $\left\{\kappa_{t}, a_{t}^{M}\right\}_{t=0}^{\infty}$ is determined, all other endogenous variables are determined as well.

\subsection{Existence, uniqueness, and stability of a steady state}

In a steady state, we have $\kappa_{t+1}=\kappa_{t}=\widetilde{\kappa}$ and $a_{t+1}^{M}=a_{t}^{M}=\widetilde{a}^{M}$, where a tilde over a variable represents a steady state under free migration. Then Eq. (38) implies that $\widetilde{\kappa}$ is proportional to $\lambda\left(a^{R}, \widetilde{a}^{M}\right)$ :

$$
\widetilde{\kappa}=B^{1 /(1-\alpha)} \lambda\left(a^{R}, \widetilde{a}^{M}\right) .
$$

Substituting Eq. (42) into Eq. (41), and noting that $2+\rho+\alpha+(1+$ $\rho+\alpha) \alpha[1 /(1-\alpha)]=(2+\rho) /(1-\alpha), \widetilde{a}^{M}$ is determined by:

$$
\left(E^{N}\left(\widetilde{a}^{M}\right)-f\right) /\left(E^{N}\left(\widetilde{a}^{M}\right)-f-g\right)=B^{-1 /(1-\alpha)} \Rightarrow \widetilde{a}^{M}=\widetilde{a}^{M}(f, g, B) .
$$

Proposition 2 In the dynamic system consisting of Eqs. (38) and (41), there exists a unique steady state $\left(\widetilde{\kappa}, \widetilde{a}^{M}\right)$ such that $\widetilde{a}^{M} \in\left(a^{R}, 1\right)$ if:

$$
\left(1-B^{1 /(1-\alpha)}\right)\left(E^{N}\left(a^{R}\right)-f\right)<g<\left(1-B^{1 /(1-\alpha)}\right)\left(E^{N}(1)-f\right) .
$$

Moreover, the dynamic system is saddle-path stable around the steady state. During the transition, $a_{t}^{M}$ moves in the same direction as $\kappa_{t}$.

Proof. From Proposition 1, there exists a unique $\widetilde{a}^{M} \in\left(a^{R}, 1\right)$ if the second $\left.\overline{\left(K_{t}^{S} / L_{t}^{S}\right) /\left(K_{t}^{N} / L_{t}^{N}\right)=\kappa_{t} / \lambda\left(a^{R}, a_{t}^{M}\right.}\right)$. 
and third conditions of Assumption 3 hold in the steady state. From Eq. (43), they are equivalent to $\left(E^{N}\left(a^{R}\right)-f\right) /\left(E^{N}\left(a^{R}\right)-f-g\right)>B^{-1 /(1-\alpha)}$ and $\left(E^{N}(1)-f\right) /\left(E^{N}(1)-f-g\right)<B^{-1 /(1-\alpha)}$, respectively. Solving these inequalities for $g$, we obtain Eq. (44).

On the other hand, $\widetilde{\kappa}$ is uniquely determined from Eq. (42) because $\lambda\left(a^{R}, \widetilde{a}^{M}\right)$ is monotonically increasing in $\widetilde{a}^{M}$ from Eq. (40).

As for stability, linearizing Eqs. (38) and (41) around the steady state, and using Eqs. (40), (42), and (43), we obtain:

$$
\left[\begin{array}{c}
\kappa_{t+1}-\widetilde{\kappa} \\
a_{t+1}^{M}-\widetilde{a}^{M}
\end{array}\right]=J\left[\begin{array}{c}
\kappa_{t}-\widetilde{\kappa} \\
a_{t}^{M}-\widetilde{a}^{M}
\end{array}\right] ;
$$

$$
\begin{aligned}
J & \equiv\left[\begin{array}{ll}
j_{11} & j_{12} \\
j_{21} & j_{22}
\end{array}\right], \\
j_{11} & \equiv \alpha \in(0,1) \\
j_{12} & \equiv(1-\alpha) \widetilde{\kappa} \lambda_{M} / \lambda>0, \\
j_{21} & \equiv-(1 / \Delta)(1+\rho+\alpha) \alpha / \widetilde{\kappa}<0, \\
j_{22} & \equiv(1 / \Delta)\left\{\Delta+(1+\rho+\alpha) \alpha \lambda_{M} / \lambda+(2+\rho) E_{a}^{N} g /\left[\left(E^{N}-f\right)\left(E^{N}-f-g\right)\right]\right\}>1, \\
\Delta & \equiv(1-\alpha) \lambda_{M} / \lambda>0 .
\end{aligned}
$$

In Appendix A, we show that the characteristic equation associated with the Jacobian matrix $J$ of Eq. (45) with one state variable and one control variable has two eigenvalues with $0<\lambda_{1}<1<\lambda_{2}$, and thus the dynamic system is saddle-path stable. Finally, it is verified in Appendix A that the stable arm is upward-sloping in the $\left(\kappa_{t}, a_{t}^{M}\right)$ plane, meaning that $\kappa_{t}$ and $a_{t}^{M}$ move in the same direction during the transition.

Fig. 2 describes the equilibrium path in the $\left(\kappa_{t}, a_{t}^{M}\right)$ plane. Appendix A verifies that both the $\kappa_{t+1}=\kappa_{t}$ and $a_{t+1}^{M}=a_{t}^{M}$ loci are upward-sloping, and that the former is steeper than the latter. We have $\kappa_{t+1}>\kappa_{t}$ above the $\kappa_{t+1}=\kappa_{t}$ locus, whereas $\kappa_{t+1}<\kappa_{t}$ below it. As more people return home (i.e., $a_{t}^{M}$ increases), country $S$ becomes relatively more populated, and so it accumulates capital more relatively to the next period. On the other hand, 
$a_{t+1}^{M}<a_{t}^{M}$ to the right of the $a_{t+1}^{M}=a_{t}^{M}$ locus, whereas $a_{t+1}^{M}>a_{t}^{M}$ to the left of it. This is because an increase in $\kappa_{t}$ increases the net benefit of returning home, which should be compensated for by a decrease in country $S$ 's working population for the next period. The steady state is found at point $\mathrm{B}$, the intersection of the $\kappa_{t+1}=\kappa_{t}$ and $a_{t+1}^{M}=a_{t}^{M}$ loci. The stable arm, drawn by arrows toward point B, is upward-sloping but flatter than the $a_{t+1}^{M}=a_{t}^{M}$ locus.

Proposition 2 has interesting implications. Suppose that country $S$ is initially poor in capital stock: $\kappa_{0}<\widetilde{\kappa}$ in Figure 1 . Then $a_{0}^{M}$ is found at point $\mathrm{A}$ on the stable arm. After that, the equilibrium point moves to the northeast along the stable arm until it reaches point B. As capital gradually accumulates in country $S$, more and more students choose to return home after finishing their studies in country $N$. This matches the fact that a lot more Chinese and Indian students are returning to their respective home countries in recent years, while 20 some years ago few of them did that.

\section{Comparative dynamics}

Having shown that our model exhibits well-behaved dynamics, we next examine the effects of exogenous shocks on some endogenous variables. We are particularly interested in changes in the fixed costs of studying and working abroad because they will directly affect the distribution of migration types.

\subsection{A decrease in the fixed cost of studying abroad}

Totally differentiating Eqs. (38) and (41) with $d f \neq 0$, and using Eqs. (39), (40), (42), and (43), we have:

$\left[\begin{array}{c}d \kappa_{t+1} \\ d a_{t+1}^{M}\end{array}\right]=J\left[\begin{array}{c}d \kappa_{t} \\ d a_{t}^{M}\end{array}\right]+\left[\begin{array}{c}0 \\ -(1 / \Delta)(2+\rho) g /\left[\left(E^{N}-f\right)\left(E^{N}-f-g\right)\right]\end{array}\right] d f$

Letting $\kappa_{t+1}=\kappa_{t}=\widetilde{\kappa}$ and $a_{t+1}^{M}=a_{t}^{M}=\widetilde{a}^{M}$, we obtain: 


$$
\begin{aligned}
\partial \widetilde{\kappa} / \partial f & =-(1 / \varphi(1)) j_{12}(1 / \Delta)(2+\rho) g /\left[\left(E^{N}-f\right)\left(E^{N}-f-g\right)\right]>0, \\
\partial \widetilde{a}^{M} / \partial f & =-(1 / \varphi(1))\left\{-\left(j_{11}-1\right)(1 / \Delta)(2+\rho) g /\left[\left(E^{N}-f\right)\left(E^{N}-f-g\right)\right]\right\}>0,
\end{aligned}
$$

where $\varphi(\lambda)$ is the characteristic polynomial associated with $J$, and $\varphi(1)<$ 0 .

In Fig. 3, suppose that we are originally at point B, the old steady state. A decrease in $f$ shifts the $a_{t+1}^{M}=a_{t}^{M}$ locus down to $\left(a_{t+1}^{M}=a_{t}^{M}\right)^{\prime}$, but leaves the $\kappa_{t+1}=\kappa_{t}$ locus unchanged. The new steady state moves to point $\mathrm{D}$, which is to the southwest of point $\mathrm{B}$ on the $\kappa_{t+1}=\kappa_{t}$ locus. The new stable arm is drawn by arrows toward point $\mathrm{D}$. In the initial period, the equilibrium point jumps down from point $\mathrm{B}$ to point $\mathrm{C}$ on the new stable arm. Then the equilibrium point gradually moves to the southwest along the new stable arm to point $\mathrm{D}$. As a result, both $\widetilde{a}^{M}$ and $\widetilde{\kappa}$ decrease.

The above adjustment process can be interpreted as follows. In period 0 , a decrease in $f$ increases the effective labor of both types $R$ and $M$ by the same amount. Then the utility of type $M$ with a smaller effective labor increases more than type $R$ due to diminishing marginal utility. This induces some type $R$ whose ability was close to $\widetilde{a}^{M}$ in the old steady state to switch to type $M$. Since the working population of country $S$ decreases due to the increase in the fraction of permanent migrants, the relative supply of capital in country $S$ to country $N$ decreases for the next period. In period 1 , the decrease in $\kappa_{1}$ reduces the utility of type $R$ relative to type $M$, which further decreases $a_{1}^{M}$ and hence $\kappa_{2}$. This process continues until the equilibrium point reaches point D.

Although the fraction of permanent migrants $1-\widetilde{a}^{M}$ surely increases with a decrease in $f$, it is unclear how the fraction of return migrants $\widetilde{a}^{M}-a^{R}$ changes because $a^{R}$ also decreases from Proposition 1. More specifically, Eqs. (12) and (28) imply that:

$$
d a^{R} / d f=1 /\left(E_{a}^{N}-E_{a}^{S}\right)>0 .
$$


A decrease in $f$ increases $\widetilde{a}^{M}-a^{R}$ if and only if $\partial \widetilde{a}^{M} / \partial f-d a^{R} / d f<0$, or $d a^{R} / d f>\partial \widetilde{a}^{M} / \partial f>0$. This is more likely, the smaller is the difference between the slopes of $E^{N}\left(a_{t}^{S}\right)$ and $E^{S}\left(a_{t}^{S}\right)$. Our results are summarized in the following proposition:

Proposition 3 In the steady state, a permanent decrease in the fixed cost of studying abroad: (i) decreases the fraction of non-migrants $a^{R}$; (ii) increases the fraction of return migrants $\widetilde{a}^{M}-a^{R}$ if $E_{a}^{N}-E_{a}^{S}$ is sufficiently small; (iii) increases the fraction of permanent migrants $1-\widetilde{a}^{M}$; and (iv) decreases the relative supply of capital in the source country $\widetilde{\kappa}$.

Example If the acquired effective labor function is specified as $h^{i}\left(e_{t}^{i}, a_{t}^{i}\right)=$ $H^{i} e^{a_{t}^{i}}\left(e_{t}^{i}\right)^{\gamma} ; 0<H^{S}<H^{N}, \gamma \in(0,1)$, where $e$ is Euler's number (i.e., the base of the natural logarithm), then we obtain $d a^{R} / d f=(1-\gamma) / f$ and $\partial \widetilde{a}^{M} / \partial f=(1-\gamma) /\left[\left(1-B^{1 /(1-\alpha)}\right)^{-1} g-1+f\right]$. Since $\left(1-B^{1 /(1-\alpha)}\right)^{-1} g>$ $E^{N}\left(a^{R}\right)-f$ from Eq. (44), and $E^{N}\left(a^{R}\right)-f=1+\left[\left(H^{S}\right)^{1 /(1-\gamma)} /\left(\left(H^{N}\right)^{1 /(1-\gamma)}-\right.\right.$ $\left.\left.\left(H^{S}\right)^{1 /(1-\gamma)}\right)\right] f>1$, we have $d a^{R} / d f>\partial \widetilde{a}^{M} / \partial f$. Therefore, a decrease in $f$ increases $\widetilde{a}^{M}-a^{R}$ under this specification.

\subsection{A decrease in the fixed cost of working abroad}

In the same way as the previous case, we can show that:

$$
\begin{aligned}
\partial \widetilde{\kappa} / \partial g & =-(1 / \varphi(1)) j_{12}(1 / \Delta)(2+\rho) /\left(E^{N}-f-g\right)>0, \\
\partial \widetilde{a}^{M} / \partial g & =-(1 / \varphi(1))\left[-\left(j_{11}-1\right)(1 / \Delta)(2+\rho) /\left(E^{N}-f-g\right)\right]>0 .
\end{aligned}
$$

Since $a^{R}$ is independent of $g$, we immediately obtain the following proposition:

Proposition 4 In the steady state, a permanent decrease in the fixed cost of working abroad: (i) leaves the fraction of non-migrants $a^{R}$ unchanged; (ii) decreases the fraction of return migrants $\widetilde{a}^{M}-a^{R}$; (iii) increases the fraction of permanent migrants $1-\widetilde{a}^{M}$; and (iv) decreases the relative supply of capital in the source country $\widetilde{\kappa}$. 
A dynamic implication of Propositions 4 and 5 is that facilitating either studying or working abroad discourages capital accumulation in the source country. This is simply because capital is supplied from the savings of the working population of the old generation. As more people decide to work abroad, the source country has less workers. Then they save less in the aggregate even if the return migrants save more. We next consider how we can encourage studying abroad without discouraging capital accumulation.

\subsection{Offsetting changes in the fixed costs of studying and working abroad}

Suppose that a decrease in the fixed cost of studying abroad is combined with an offsetting increase in the fixed cost of working abroad: $d f<0, d g=$ $-d f>0$. From the results in sections 4.1 and 4.2 , we immediately obtain:

$$
\begin{aligned}
d \widetilde{\kappa} /\left.d f\right|_{d g=-d f} & =\partial \widetilde{\kappa} / \partial f-\partial \widetilde{\kappa} / \partial g \\
& =-(1 / \varphi(1)) j_{12}(1 / \Delta)(2+\rho)\left[-1 /\left(E^{N}-f\right)\right]<0, \\
d \widetilde{a}^{M} /\left.d f\right|_{d g=-d f} & =\partial \widetilde{a}^{M} / \partial f-\partial \widetilde{a}^{M} / \partial g \\
& =-(1 / \varphi(1))\left\{-\left(j_{11}-1\right)(1 / \Delta)(2+\rho)\left[-1 /\left(E^{N}-f\right)\right]\right\}<0 .
\end{aligned}
$$

Remembering the fact that $a^{R}$ is increasing in $f$ but independent of $g$, we reach the following proposition:

Proposition 5 In the steady state, a permanent decrease in the fixed cost of studying abroad and an offsetting permanent increase in the fixed cost of working abroad: (i) decrease the fraction of non-migrants $a^{R}$; (ii) increase the fraction of return migrants $\widetilde{a}^{M}-a^{R}$; (iii) decrease the fraction of permanent migrants $1-\widetilde{a}^{M}$; and (iv) increase the relative supply of capital in the source country $\widetilde{\kappa}$.

In view of Eq. (41), a decrease in $f$ and an offsetting increase in $g$ raises the net benefit of returning home. This induces some of the permanent migrants to return to their home country. Moreover, from Eq. (38), the 
increased working population in the source country increases its relative supply of capital for the next period, which further makes returning home more desirable. Thus, we can promote studying abroad and returning home at the same time, which helps the source country turn "brain drain" into "brain gain".

\subsection{Individual utility in the steady state}

From Eqs. (20), (35), (36), and (37), individual utility in the steady state is expressed as:

$$
\begin{aligned}
& \widetilde{V}^{S}\left(a_{t}^{S}\right)=D+(2+\rho+\alpha) \ln B^{S}+(1+\rho+\alpha) \alpha \ln \widetilde{k}^{S}+(2+\rho) \ln E^{S}\left(a_{t}^{S}\right), \\
& \widetilde{V}^{R}\left(a_{t}^{S}\right)=D+(2+\rho+\alpha) \ln B^{S}+(1+\rho+\alpha) \alpha \ln \widetilde{k}^{S}+(2+\rho) \ln \left(E^{N}\left(a_{t}^{S}\right)-f\right), \\
& \widetilde{V}^{M}\left(a_{t}^{S}\right)=D+(2+\rho+\alpha) \ln B^{N}+(1+\rho+\alpha) \alpha \ln \widetilde{k}^{N}+(2+\rho) \ln \left(E^{N}\left(a_{t}^{S}\right)-f-g\right), \\
& \widetilde{V}^{N}\left(a_{t}^{N}\right)=D+(2+\rho+\alpha) \ln B^{N}+(1+\rho+\alpha) \alpha \ln \widetilde{k}^{N}+(2+\rho) \ln E^{N}\left(a_{t}^{N}\right) .
\end{aligned}
$$

Comparing Eqs. (33) and (34) with Eq. (19), each country's capital/effective labor ratio in the steady state under free migration is the same as that under autarky, and is independent of $f$ and $g$ :

$$
\begin{aligned}
\widetilde{k}^{S} & =\left[(1-\alpha) B^{S} /(2+\rho)\right]^{1 /(1-\alpha)}=\bar{k}^{S}, \\
\widetilde{k}^{N} & =\left[(1-\alpha) B^{N} /(2+\rho)\right]^{1 /(1-\alpha)}=\bar{k}^{N} .
\end{aligned}
$$

We first consider a decrease in the fixed cost of studying abroad from $f$ to $f^{\prime}(<f)$. Then both $a^{R}$ and $\widetilde{a}^{M}$ decrease to $a^{R \prime}\left(<a^{R}\right)$ and $\widetilde{a}^{M^{\prime}}\left(<\widetilde{a}^{M}\right)$, respectively. It is clear that the utility of all households born in country $N$ is unchanged in the steady state. On the other hand, the individual utility of households born in country $S$ can be examined in Fig. 4. Suppose that the utility of types $S, R$, and $M$ in the old steady state are given by curves $\widetilde{V}^{S}, \widetilde{V}^{R}$, and $\widetilde{V}^{M}$, respectively. Point A, the intersection of curves $\widetilde{V}^{S}$ and $\widetilde{V}^{R}$, determines $a^{R}$. On the other hand, curves $\widetilde{V}^{R}$ and $\widetilde{V}^{M}$ intersect at 
point B, which gives $\widetilde{a}^{M}$. A decrease in $f$ shifts both curves $\widetilde{V}^{R}$ and $\widetilde{V}^{M}$ up to curves $\widetilde{V}^{R \prime}$ and $\widetilde{V}^{M \prime}$, respectively. Both points A and B move leftward to points $\mathrm{C}$ and $\mathrm{D}$, respectively. In the illustrated case, the fractions of both permanent and return migrants increase. There emerge five groups who are differently affected by a decrease in $f:$ (i) $\widetilde{V}^{S \prime}\left(a_{t}^{S}\right)=\widetilde{V}^{S}\left(a_{t}^{S}\right)$ for $a_{t}^{S} \in$ $\left[0, a^{R \prime}\right]$; (ii) $\widetilde{V}^{R \prime}\left(a_{t}^{S}\right)>\widetilde{V}^{S}\left(a_{t}^{S}\right)$ for $a_{t}^{S} \in\left[a^{R \prime}, a^{R}\right]$; (iii) $\widetilde{V}^{R \prime}\left(a_{t}^{S}\right)>\widetilde{V}^{R}\left(a_{t}^{S}\right)$ for $a_{t}^{S} \in\left[a^{R}, \widetilde{a}^{M \prime}\right]$; (iv) $\widetilde{V}^{M \prime}\left(a_{t}^{S}\right)>\widetilde{V}^{R}\left(a_{t}^{S}\right)$ for $a_{t}^{S} \in\left[\widetilde{a}^{M \prime}, \widetilde{a}^{M}\right]$; and (v) $\widetilde{V}^{M \prime}\left(a_{t}^{S}\right)>\widetilde{V}^{M}\left(a_{t}^{S}\right)$ for $a_{t}^{S} \in\left[\widetilde{a}^{M}, 1\right]$. Groups (iii) and (v) gain simply by supplying more effective labor. On the other hand, groups (ii) and (iv) gain from changes in migration status. Overall, a decrease in the fixed cost of studying abroad does no harm to anyone in the steady state.

The effect of a decrease in the fixed cost of working abroad on individual utility can be examined similarly. When $g$ decreases to $g^{\prime \prime}(<g)$, only $\widetilde{a}^{M}$ decreases to $\widetilde{a}^{M \prime \prime}\left(<\widetilde{a}^{M}\right)$. The utility of type $M$ increases, whereas that of the rest is unchanged.

Finally, a decrease in the fixed cost of studying abroad and an offsetting increase in the fixed cost of working abroad shifts only curve $\widetilde{V}^{R}$ up. This widens the range of ability for return migrants to both sides, and their utility increases as a result. Since the amount of increase in $g$ is limited to the amount of decrease in $f$, the utility is unchanged for both permanent migrants and non-migrants.

Proposition 6 In the steady state:

1. a permanent decrease in the fixed cost of studying abroad increases the utility of all permanent and return migrants, whereas it leaves the utility of all non-migrants unchanged;

2. a permanent decrease in the fixed cost of working abroad increases the utility of all permanent migrants, whereas it leaves the utility of all return migrants and non-migrants unchanged;

3. a permanent decrease in the fixed cost of studying abroad and an offsetting permanent increase in the fixed cost of working abroad increase 
the utility of all return migrants, whereas they leave the utility of all permanent migrants and non-migrants unchanged.

Considering Propositions 3 to 6, the third option has an advantage over the first and second ones. Any single change in either $f$ or $g$ causes a tradeoff between the utility of some migrant groups and the relative supply of capital in the source country. For example, a single increase in $g$ increases $\widetilde{\kappa}$ but decreases the utility of type $M$. Oh the other hand, a combined decrease in $f$ and an offsetting increase in $g$ are free from such a tradeoff: they increase both $\widetilde{\kappa}$ and the utility of type $R$ without hurting anyone else. If the government in the source country cares about growth as well as welfare, the third option is the best.

\section{Concluding remarks}

Our analysis based on a two-country dynamic general equilibrium model has some implications for growth-enhancing migration policies. First, discouraging either studying or working abroad enables the source country to accumulate more capital, but at the expense of permanent migrants and possibly return migrants. For example, a well-known brain drain tax proposed by Bhagwati and Hamada (1974), which can be interpreted as an increase in $g$ in the present model, harms permanent emigrants. Second, however, offsetting changes in the fixed costs of studying and working abroad can be both growth-enhancing for the source country and Pareto-improving for the world. This may provide policy guidance for developing countries trying to encourage students studying abroad to return home and help develop their motherland countries.

It is considerable that returning home may require some cost. In our model, incorporating such a cost for return migration can create an additional cutoff, such that those students with the lowest abilities may not be able to pay this cost and return home. As a consequence, they could end up working illegally in the host countries after their student visas expire. Then, the students studying abroad can be divided into three groups: those with 
highest ability stay permanently with good jobs in the host country, those with middle ability choose to return home, and those with lowest ability stay illegally.

Two other possible extensions are also interesting. First, the migration costs in the model can be considered as caused by changes in taxes or subsidies. Then it would become realistic to design an appropriate tax-subsidy scheme under the government budget constraint. Second, our analysis is still limited to a neoclassical growth model with no growth in the steady state. It will be interesting to include endogenous growth, whether accumulation- or R\&D-based, and see how migration patterns interact with long-run growth.

\section{Appendix A. Transitional dynamics}

The characteristic equation associated with the Jacobian matrix $J$ of Eq. (45) is:

$\varphi(\lambda) \equiv \operatorname{det}(\lambda I-J)=\left|\begin{array}{cc}\lambda-j_{11} & -j_{12} \\ -j_{21} & \lambda-j_{22}\end{array}\right|=\lambda^{2}-\left(j_{11}+j_{22}\right) \lambda+j_{11} j_{22}-j_{12} j_{21}$.

Since $j_{11}+j_{22}>0$ and $j_{11} j_{22}-j_{12} j_{21}>0$, both eigenvalues satisfying that $\varphi(\lambda)=0$ have positive real parts. Let $\lambda_{1}$ and $\lambda_{2}$ be the two eigenvalues such that $0<\lambda_{1}<\lambda_{2}$. Moreover, evaluating $\varphi(\lambda)$ at $\lambda=1$, we have:

$$
\begin{aligned}
\varphi(1) & =1-\left(j_{11}+j_{22}\right)+j_{11} j_{22}-j_{12} j_{21} \\
& =-(1 / \Delta)(1-\alpha)(2+\rho) E_{a}^{N} g /\left[\left(E^{N}-f\right)\left(E^{N}-f-g\right)\right]<0 .
\end{aligned}
$$

This implies that $0<\lambda_{1}<1<\lambda_{2}$, ensuring saddle-path stability.

We next derive the stable arm representing the equilibrium path. The eigenvectors associated with $\lambda_{1}$ and $\lambda_{2}$ are given by $v_{1} \equiv\left[1, j_{21} /\left(\lambda_{1}-j_{22}\right)\right]^{T}$ and $v_{2} \equiv\left[1, j_{21} /\left(\lambda_{2}-j_{22}\right)\right]^{T}$, respectively. With $V \equiv\left[v_{1}, v_{2}\right]$, let us define two transformed variables $x_{t}$ and $y_{t}$ such that: 


$$
\left[\begin{array}{c}
\kappa_{t}-\widetilde{\kappa} \\
a_{t}^{M}-\widetilde{a}^{M}
\end{array}\right] \equiv V\left[\begin{array}{c}
x_{t} \\
y_{t}
\end{array}\right]
$$

Then, since Eq. (45) is rewritten as:

$$
\left[\begin{array}{c}
x_{t+1} \\
y_{t+1}
\end{array}\right]=V^{-1} J V\left[\begin{array}{l}
x_{t} \\
y_{t}
\end{array}\right]=\left[\begin{array}{cc}
\lambda_{1} & 0 \\
0 & \lambda_{2}
\end{array}\right]\left[\begin{array}{l}
x_{t} \\
y_{t}
\end{array}\right],
$$

$x_{t}$ and $y_{t}$ are solved as, respectively:

$$
\begin{aligned}
& x_{t}=\lambda_{1}^{t} x_{0}, \\
& y_{t}=\lambda_{2}^{t} y_{0} .
\end{aligned}
$$

Transforming them back, we obtain:

$$
\begin{aligned}
\kappa_{t}-\widetilde{\kappa} & =\lambda_{1}^{t} x_{0}+\lambda_{2}^{t} y_{0}, \\
a_{t}^{M}-\widetilde{a}^{M} & =\left[j_{21} /\left(\lambda_{1}-j_{22}\right)\right] \lambda_{1}^{t} x_{0}+\left[j_{21} /\left(\lambda_{2}-j_{22}\right)\right] \lambda_{2}^{t} y_{0} .
\end{aligned}
$$

Since $\lambda_{2}>1$, we must have $y_{0}=0$ for the dynamic system not to explode. Therefore, it is reduced to:

$$
\begin{aligned}
\kappa_{t}-\widetilde{\kappa} & =\lambda_{1}^{t} x_{0}, \\
a_{t}^{M}-\widetilde{a}^{M} & =\left[j_{21} /\left(\lambda_{1}-j_{22}\right)\right] \lambda_{1}^{t} x_{0} .
\end{aligned}
$$

Since $\kappa_{0}-\widetilde{\kappa}=x_{0}$ in the initial period, we finally obtain:

$$
\begin{aligned}
\kappa_{t}-\widetilde{\kappa} & =\lambda_{1}^{t}\left(\kappa_{0}-\widetilde{\kappa}\right), \\
a_{t}^{M}-\widetilde{a}^{M} & =\left[j_{21} /\left(\lambda_{1}-j_{22}\right)\right] \lambda_{1}^{t}\left(\kappa_{0}-\widetilde{\kappa}\right)=\left[j_{21} /\left(\lambda_{1}-j_{22}\right)\right]\left(\kappa_{t}-\widetilde{\kappa}\right) .
\end{aligned}
$$

The last equation shows the stable arm. Its slope in the $\left(\kappa_{t}, a_{t}^{M}\right)$ plane 
is given by:

$$
\left(a_{t}^{M}-\widetilde{a}^{M}\right) /\left.\left(\kappa_{t}-\widetilde{\kappa}\right)\right|_{S A}=j_{21} /\left(\lambda_{1}-j_{22}\right)>0 .
$$

On the other hand, from Eq. (45), the slopes of the $\kappa_{t+1}=\kappa_{t}$ and $a_{t+1}^{M}=a_{t}^{M}$ loci are calculated as, respectively:

$$
\begin{aligned}
&\left(a_{t}^{M}-\widetilde{a}^{M}\right) /\left.\left(\kappa_{t}-\widetilde{\kappa}\right)\right|_{\kappa_{t+1}=\kappa_{t}}=-\left(j_{11}-1\right) / j_{12}>0, \\
&\left(a_{t}^{M}-\widetilde{a}^{M}\right) /\left.\left(\kappa_{t}-\widetilde{\kappa}\right)\right|_{a_{t+1}^{M}=a_{t}^{M}}=-j_{21} /\left(j_{22}-1\right)>0 .
\end{aligned}
$$

It turns out that the $\kappa_{t+1}=\kappa_{t}$ locus is steeper than the $a_{t+1}^{M}=a_{t}^{M}$ locus:

$\left(a_{t}^{M}-\widetilde{a}^{M}\right) /\left.\left(\kappa_{t}-\widetilde{\kappa}\right)\right|_{\kappa_{t+1}=\kappa_{t}}-\left(a_{t}^{M}-\widetilde{a}^{M}\right) /\left.\left(\kappa_{t}-\widetilde{\kappa}\right)\right|_{a_{t+1}^{M}=a_{t}^{M}}=-\varphi(1) /\left[j_{12}\left(j_{22}-1\right)\right]>0$.

We can also see that the stable arm is flatter than the $a_{t+1}^{M}=a_{t}^{M}$ locus:

$\left(a_{t}^{M}-\widetilde{a}^{M}\right) /\left.\left(\kappa_{t}-\widetilde{\kappa}\right)\right|_{a_{t+1}^{M}=a_{t}^{M}}-\left(a_{t}^{M}-\widetilde{a}^{M}\right) /\left.\left(\kappa_{t}-\widetilde{\kappa}\right)\right|_{S A}=j_{21}\left(-1+\lambda_{1}\right) /\left[\left(j_{22}-\lambda_{1}\right)\left(j_{22}-1\right)\right]>0$. 


\section{References}

[1] Bhagwati, J., Hamada, K., 1974. The drain drain, international integration of markets for professionals and unemployment: a theoretical analysis. Journal of Development Economics 1, 19-42.

[2] Borjas, G. J., Bratsberg, B., 1996. Who leaves? the outmigration of the foreign-born. Review of Economics and Statistics 78, 165-176.

[3] Chacko, E., 2007. From brain drain to brain gain: reverse migration to Bangalore and Hyderabad, India's globalizing high tech cities. GeoJournal 68, 131-140.

[4] Djajić, S., 2008. Immigrant parents and children: an analysis of decisions related to return migration. Review of Development Economics $12,469-485$.

[5] Domingues Dos Santos, M., Postel-Vinay, F., 2003. Migration as a source of growth: the perspective of a developing country. Journal of Population Economics 16, 161-175.

[6] Dustmann, C., 1997. Return migration, uncertainty and precautionary savings. Journal of Development Economics 52, 295-316.

[7] Dustmann, C., 2003. Children and return migration. Journal of Population Economics 16, 815-830.

[8] Dustmann, C., Fadlon, I., Weiss, Y., 2011. Return migration, human capital accumulation and the brain drain. Journal of Development Economics $95,58-67$.

[9] Fujishima, S., 2013. Growth, agglomeration, and urban congestion. Journal of Economic Dynamics and Control 37, 1168-1181.

[10] Galor, O., Stark, O., 1990. Migrants' savings, the probability of return migration and migrants' performance. International Economic Review $31,463-467$. 
[11] Ivanova, V., 2013. Return migration: existing policies and practices in Bulgaria, in: Zwania-Roessler, I., Ivanova, V. (Eds.), Welcome Home? Challenges and Chances of Return Migration. German Marshall Fund of the United States, Washington, DC, pp. 8-18.

$<$ http://www.gmfus.org/wp-content/blogs.dir/1/files_mf/1358538301tfmireturnmigration.pdf>, last accessed February 27, 2014.

[12] Lange, T., 2013. Return migration of foreign students and non-resident tuition fees. Journal of Population Economics 26, 703-718.

[13] MATT, 2013. The US/Mexico cycle: end of an era. $<$ http://www.matt.org/uploads/2/4/9/3/24932918/returnmigration_top_line_www.pdf >, last accessed February 27, 2014.

[14] Zweig, D., 2006. Competing for talent: China's strategies to reverse the brain drain. International Labour Review 145, 65-90. 


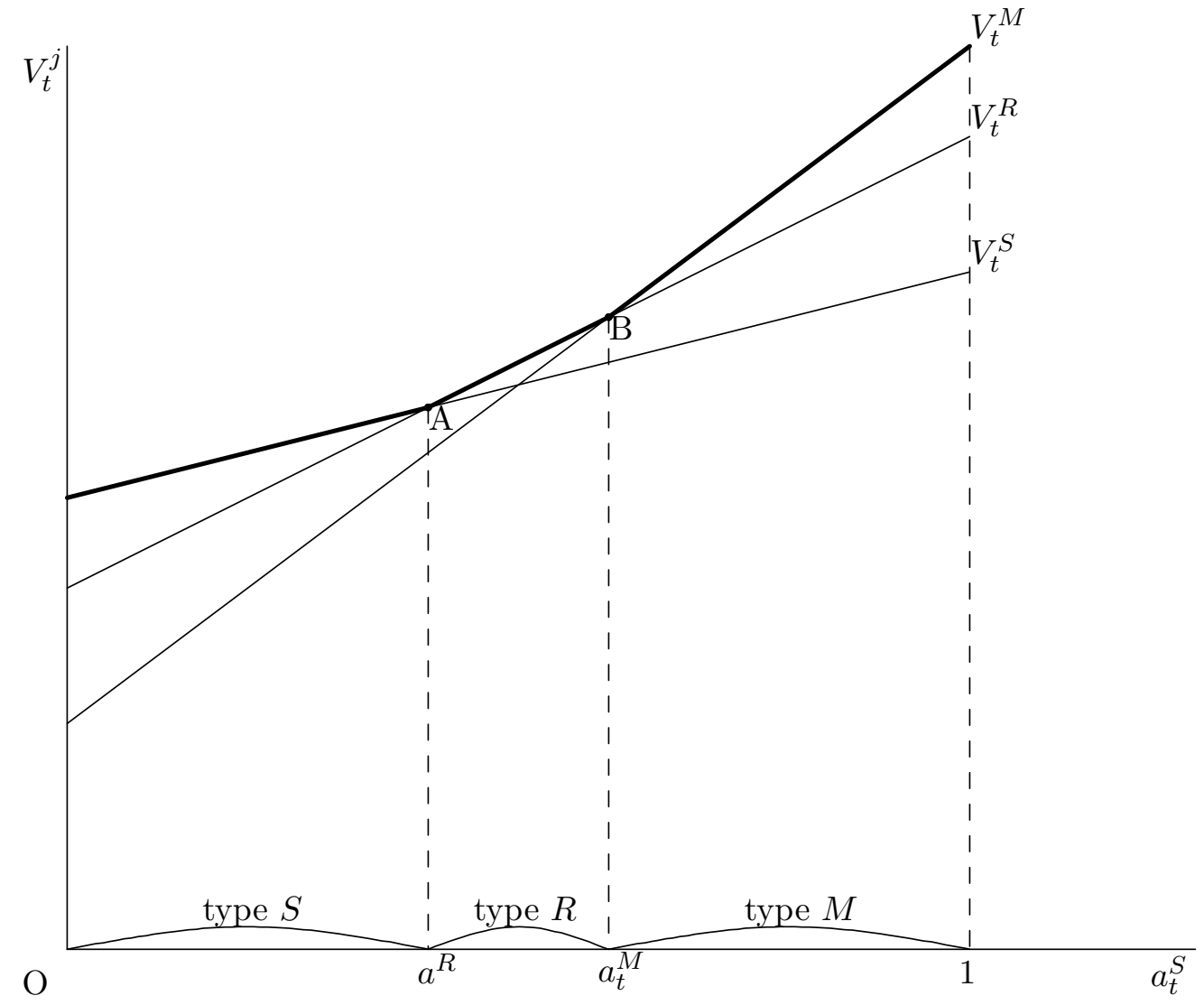

Fig. 1. The distribution of migration types. 


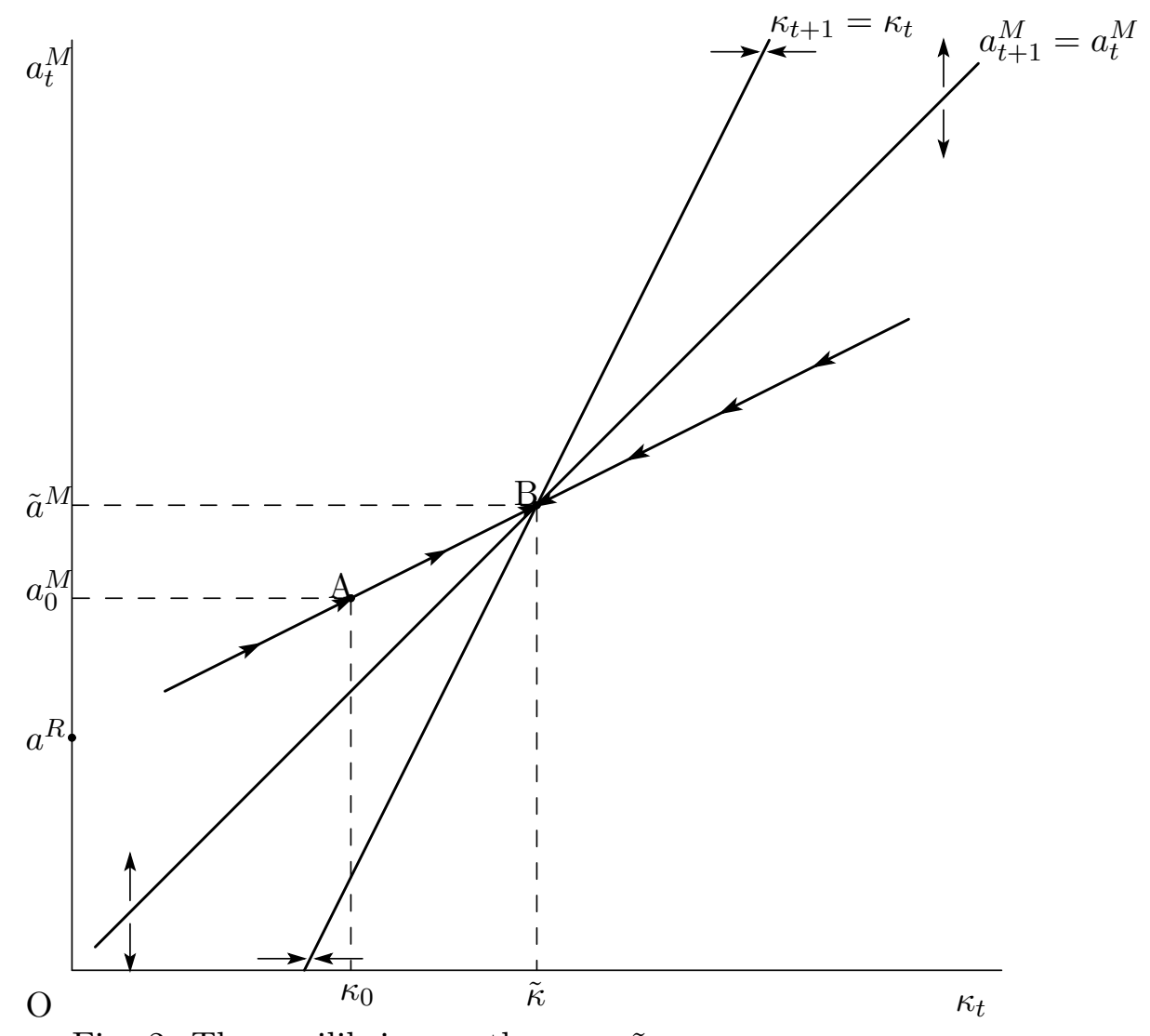

Fig. 2. The equilibrium path: $\kappa_{0}<\tilde{\kappa}$. 


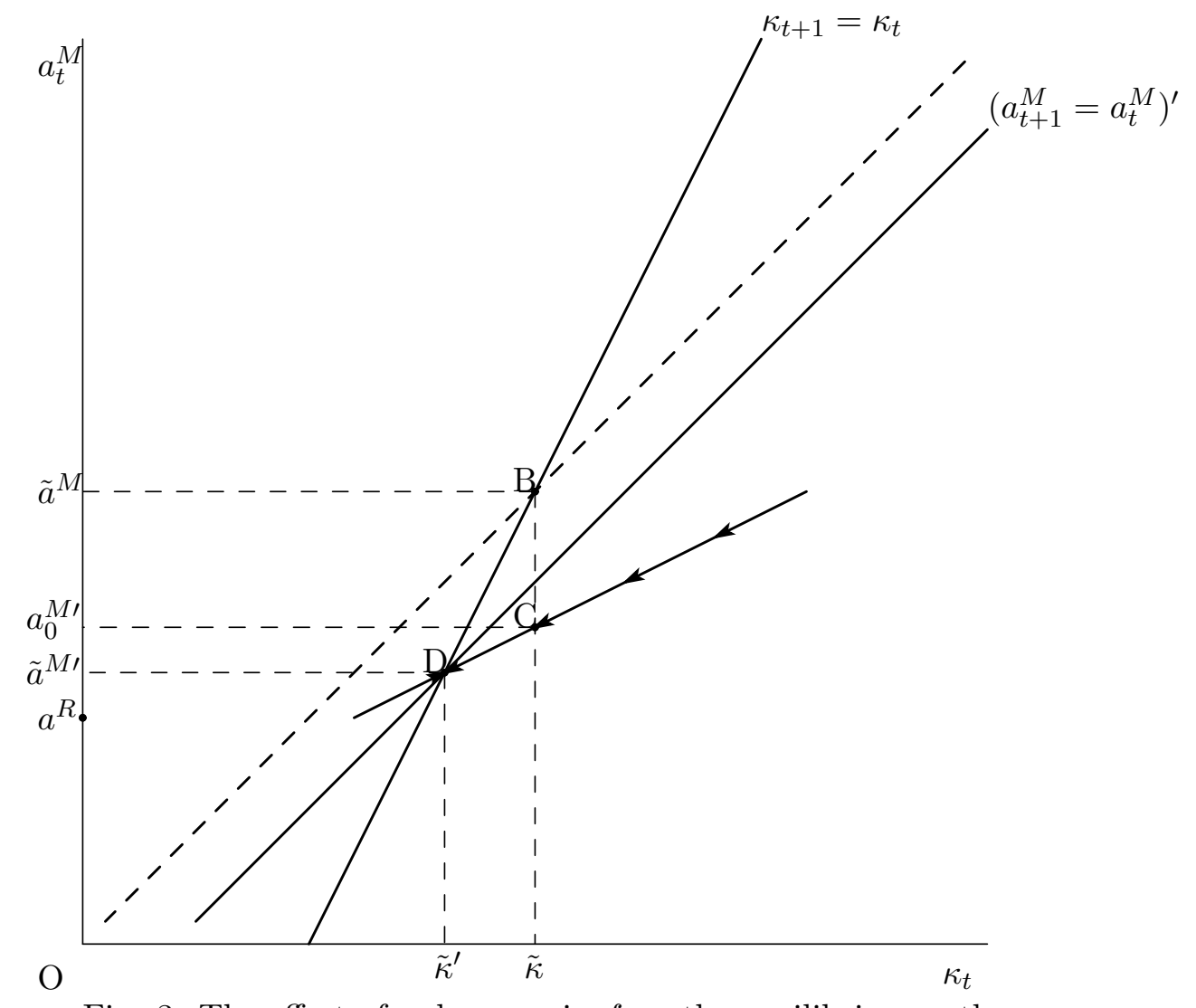

Fig. 3. The effect of a decrease in $f$ on the equilibrium path. 


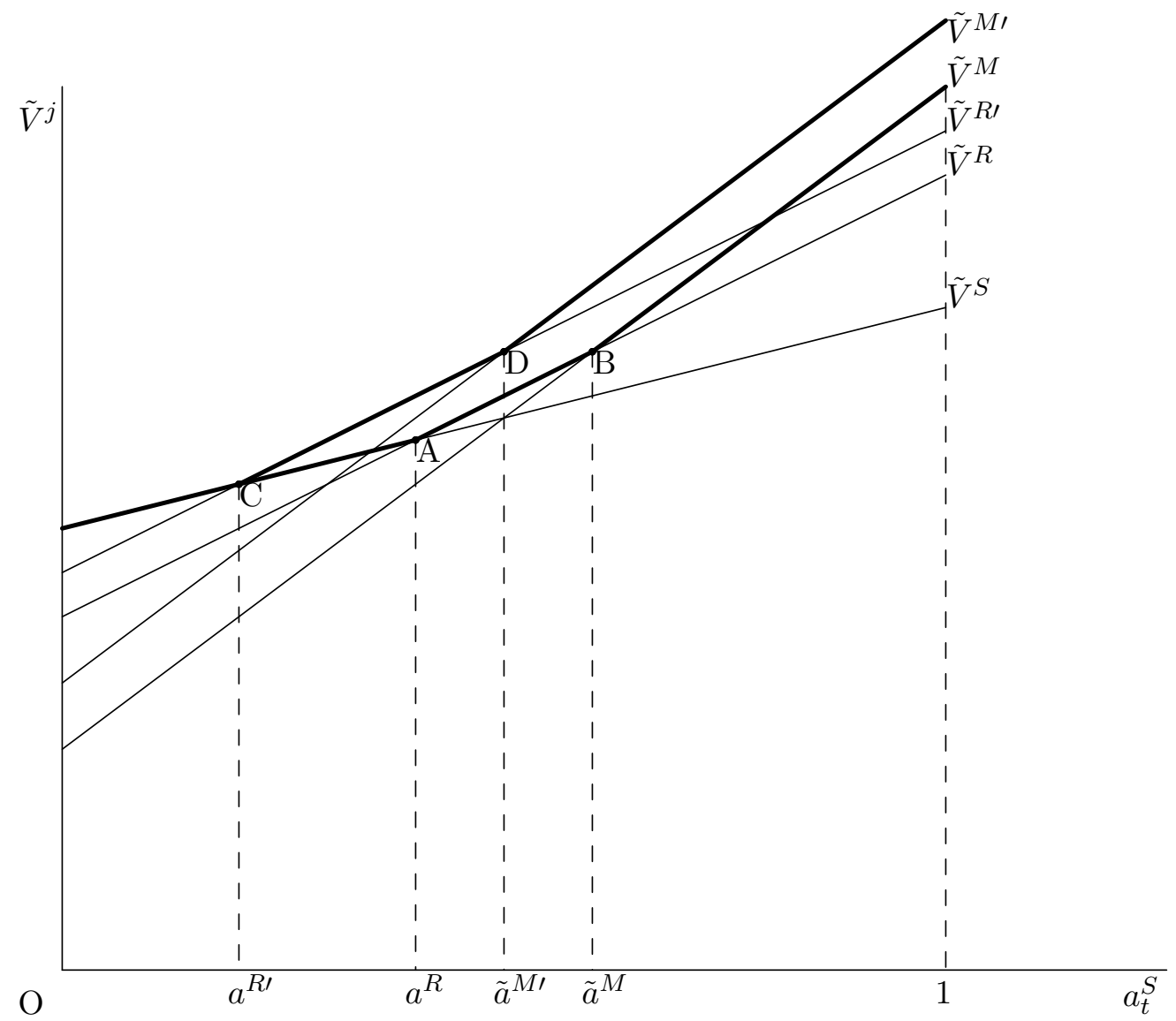

Fig. 4. The effect of a decrease in $f$ on individual utility in the steady state. 